\title{
A Novel Approach to Tumor Suppression with Microencapsulated Recombinant Cells
}

\author{
PASQUALE CIRONE, ${ }^{1}$ JACQUELINE M. BOURGEOIS, ${ }^{2}$ RICHARD C. AUSTIN, $, 2,3$ \\ and PATRICIA L. CHANG ${ }^{1,4}$
}

\begin{abstract}
A novel approach to cancer gene therapy is to implant microcapsules containing nonautologous cells engineered to secrete molecules with antineoplastic properties. The efficacy of this treatment is now tested in a mouse model bearing HER-2/neu-positive tumors. Nonautologous mouse myoblasts $\left(\mathrm{C}_{2} \mathrm{C}_{12}\right)$ were genetically modified to secrete interleukin-2 linked to the Fv region of a humanized antibody with affinity to HER-2/neu. The resulting fusion protein, sFvIL-2, would encompass immune-stimulatory cytokine activity now targeted to the HER-2/neu-expressing tumor. These recombinant cells were then immunoprotected with alginate-polyL-lysine-alginate microcapsules before implantation into tumor-bearing mice. Treatment with these encapsulated cells led to a delay in tumor progression and prolonged survival of the animals. The long-term efficacy was limited by an inflammatory reaction against the implanted microcapsules probably because of the secreted cytokine and antigenic response against the xenogeneic fusion protein itself. However, over the short term (initial 2 weeks), efficacy was confirmed when a significant amount of biologically active interleukin-2 was detected systemically, and targeting of the fusion protein to the HER-2/neu-expressing tumor was shown immunohistochemically. The tumor suppression in the treated animals was associated with increased apoptosis and necrosis in the tumor tissue, thus demonstrating successful targeting of the antiproliferative effect to the tumors by this delivery paradigm. In conclusion, this new approach to systemic cancer gene therapy needs to be modified to provide long-term delivery, but has demonstrated short-term efficacy and potential to become a cost-effective, benign, and non-viral-based adjunct to the current armory of anticancer strategies.
\end{abstract}

\section{OVERVIEW SUMMARY}

Immunoisolation provides a potentially safe and effective method of delivering recombinant therapeutic molecules. Its application as a drug-delivery platform for the treatment of cancer has shown promising developments recently. In this approach, a nonautologous cell line is genetically modified to secrete a recombinant product with potential for tumor suppression. Such a cell line may be implanted without graft rejection into all patients with similar neoplastic disease. We use a mouse model of human breast cancer overexpressing the HER-2/neu receptor to test the potential efficacy of delivering a targeted interleukin-2 for the immunotherapy of tumors. This has now been shown to be effective in tumor suppression and prolonged survival.

\section{INTRODUCTION}

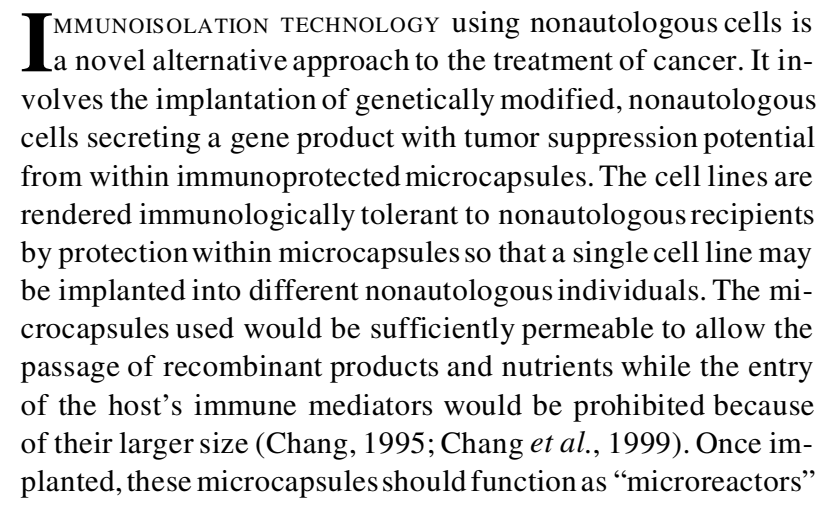

${ }^{1}$ Departments of Biology, ${ }^{2}$ Departments of Molecular Medicine and Pathology and ${ }^{4}$ Pediatrics, ${ }^{3}$ Civic Hospitals Research Centre, McMaster University, Hamilton, Ontario, Canada, L8N 3 Z5. 
to deliver a constitutive and continuous source of the antineoplastic recombinant protein, thus circumventing the problems of toxicity, limited half-lives, variation in circulating levels, and repetitive administration of bolus protein injection.

The concept of gene therapy with immunoisolation targeting mendelian inherited diseases is relatively straightforward. A previously missing protein product caused by the genetic mutation is now provided continuously with the "microreactors," which are the encapsulated cells genetically modified to secrete the required protein. The efficacy of this approach has now been demonstrated in several genetic diseases in murine models, e.g., growth-hormone deficiency in dwarfism (Al-Hendy et al., 1995, 1996), $\beta$-glucuronidase deficiency in the lysosomal storage disease MPSVII (Ross et al., 2000a,b), and factor IX in hemophilia B (Van Raamsdonk et al., 2002). However, the treatment of cancer with this approach is highly dependent on the nature of the cancer and type of molecules chosen for the tumor suppression. In this study, we chose a tumor expressing the surface antigen HER-2/neu, and an antitumor recombinant molecule encoded by the single chain $\mathrm{Fv}$ region ( $\mathrm{sFv}$ ) of a humanized monoclonal antibody recognizing human HER-2 fused to the cytokine, interleukin-2 (IL-2). HER-2/neu is a proto-oncogene encoding a 185-kd transmembrane receptor tyrosine kinase (Hynes et al., 1994). Because the amplification and overexpression of this gene have been described in several human cancers including mammary and ovarian carcinomas (Cirisano et al., 1996; Baselga et al., 1997; Meden et al., 1997), it serves as a practical target for specific cancer therapeutic strategies (Baselga et al., 1996; Pegram et al., 1998). Fusion of anti-HER2 sFv to IL-2 could then potentially allow targeting of a potent immune stimulatory cytokine (Gillis et al., 1978) to HER-2/neuexpressing tumors in vivo, and provoke an IL-2-driven immune reaction against the tumor cells (Xiang et al., 1994). Such targeted fusion proteins have been shown to stimulate the cell-mediated killing activity of cytotoxic $\mathrm{T}$ lymphocytes (CTLs) (Gillies et al., 1992; Xiang et al., 1994; Becker et al., 1996), in addition to lymphokine activated killer (LAK) cells. Immunotherapy via the administration of recombinant IL-2 has been shown to be of value in the treatment of patients with advanced melanoma or renal cell carcinoma (Rosenberg, 1997; Hoffman and Figlin, 2000) but in vivo efficacy of recombinant IL-2 treatment has been limited by its associated severe systemic toxicity and difficulties in maintaining prolonged high concentration of the cytokine in the tumor microenvironment (Rosenstein et al., 1986; Rosenberg et al., 1989). Because IL-2 is known to have a short half-life in serum, it is required in high doses to induce a therapeutic effect, thus further contributing to its toxicity (Siegel et al., 1991; Addison et al., 1995).

We hypothesize that the application of microencapsulation to deliver systemically and continuously a low level of the sFv-IL-2 immunoconjugate targeted to the tumor may overcome some of the above problems and serves as a novel paradigm for cancer treatment. This fusion protein was shown to retain both IL-2 bioactivity as well as HER-2/neu binding affinity (Li et al., 1999). Hence, the delivery of this bifunctional fusion protein would provide an effective method of targeting therapeutic doses of the cytokine IL-2 to HER2/neu-positive tumors.

\section{MATERIALS AND METHODS}

\section{Cell lines}

Mammalian expression plasmid-encoding sFvIL-2 (pcDNAH520C9sFv-hIL-2) was constructed as described previously ( $\mathrm{Li}$ et al., 1999) by fusing the $\mathrm{sFv}$ antibody cDNA versus human HER-2 from a baculovirus expression plasmid pAcHCx$5209 \mathrm{sFv}$ to the wild-type human IL-2 cDNA from plasmid pLW46. pcDNA-H520C9sFv-hIL-2 was transfected into a mouse myoblast cell line derived from $\mathrm{CH} 3$ mice, $\mathrm{C}_{2} \mathrm{C}_{12}$ (ATCC, Rockville, MD; catalog \#CRL-1772) by calcium phosphate precipitation (Chang, 1994), selected with G418 and screened with enzyme-linked immunosorbent assay (ELISA) for human interleukin-2 (hIL-2) as described previously (Li et $a l ., 1999)$, using a secondary antibody of goat anti-rabbit immunoglobulin G (IgG)/alkaline phosphatase conjugate (Gibco BRL, Ontario, Canada). Human 293 cells stably transfected with the H520C9sFvIL-2-expressing plasmid were generated as described (Li et al., 1999) and used as a positive control for sFvIL-2 expression.

B16/neu mouse cells genetically modified from a B16/F0 parental cell line to express human HER-2/neu on its cell surface was a generous gift from Dr. Louis Weiner, Fox Chase Cancer Center, Philadelphia, PA. The B16/neu and the 293 cells were maintained in Dulbecco's minimal media supplemented with $10 \%$ fetal bovine serum (FBS), $1 \%$ penicillin/streptomycin and 1.2 $\mathrm{mg} / \mathrm{ml}$ of G418. CTLL2 cells (ATCC, Manassas, VA) used for the IL-2 bioassay (Gillis et al., 1978) were maintained in supplemented RPMI media with 100 IU IL-2 to allow for rapid growth.

\section{Animals}

Five- to 6-week old C57BL/6 (Charles River, Ontario, Canada) female mice were used in accordance with Canadian Institutional Animal Care guidelines. Serum from orbital bleeds or cardiac punctures was stored at $-70^{\circ} \mathrm{C}$ until use.

The tumor model was developed by injecting $5 \times 10^{6}$ B16/neu cells into the left flank of the mice. Tumor dimensions were measured with calipers to estimate the volume according to $\mathrm{V}=a^{2} b / 2$, where $a$ is the longest diameter and $b$ the shortest (Heike et al., 1997). Mice were killed when the tumor volume reached $1 \mathrm{~cm}^{3}$ or 28 days posttumor cell injection. All mice arriving at the end point were killed with isofluorane followed by rapid cervical dislocation.

\section{Microencapsulation}

Alginate-Poly-L-Lysine-Alginate (APA) microcapsules containing either parental $\mathrm{C} 2 \mathrm{C} 12$ cells or the derivative $\mathrm{C}_{2} \mathrm{C}_{12}$ sFvIL-2 expressing the immunoconjugate were constructed as previously described (Peirone et al., 1998; Van Raamsdonk et al., 2000). Briefly, cells were resuspended in filtered $1.5 \%$ alginate (Improved Kelmar, a gift from the $\mathrm{Nu}$ traSweet Kelco Company, San Diego, CA) at a concentration of 2 million cells per milliliter of alginate solution, extruded through a 27-gauge needle under constant rate and pressure into $1.1 \% \mathrm{CaCl}_{2}$, followed by a series of washes whereby coatings of poly-L-lysine and alginate were added. The resulting APA-microencapsulated cells were used immediately for implantation. 


\section{Western blot to detect $s F v I L-2$ and tissue preparation}

Western blots were performed according to standard procedures (Sambrook et al., 1989). Tissue extracts were prepared by sonicating (at 30 -sec intervals) in homogenization buffer ( 25 $\mathrm{m} M$ Tris, $0.1 M \mathrm{NaCl}, 0.2 \%$ Triton X-100, pH 7.6) using 100 $\mathrm{mg}$ of wet weight tissue per $100 \mu \mathrm{l}$ of buffer and centrifuging at 14,000 revolutions per minute (rpm) for $30 \mathrm{~min}$ (in an Eppendorf centrifuge kept at $10^{\circ} \mathrm{C}$ ). The supernatant was stored at $-70^{\circ} \mathrm{C}$ until use. For the detection of sFvIL-2, the primary and secondary antibodies were as used in the ELISA described above. Bands were visualized with BCIP and NBT according to the manufacturer's protocols (Gibco BRL, Ontario, Canada).

\section{CTLL2 assay}

IL-2 biologic activity was determined by proliferation of IL2-dependent CTLL-2 (Gillis et al., 1978) using alamarBlue (AccuMed, Westlake, $\mathrm{OH}$ ) according to the supplier's instruction at the end of an overnight incubation to measure proliferative activity of IL-2.

\section{Anti-sFvIL-2 antibody assay}

The titer of antibodies produced by the mice against the transgene product was quantified with a competition assay against 293sFvIL-2-treated media. One microliter serum samples from mice were added in the antigen-binding step of the ELISA for IL-2 (Li et al., 1999). The loss of detectable IL-2 was taken as neutralizing activity of the given sample.

\section{Immunohistochemistry and histology}

Tissues were fixed and processed for paraffin sectioning and hematoxylin and eosin $(\mathrm{H} \& \mathrm{E})$ staining by standard protocols (Histology Laboratory, McMaster University Hospital, Hamilton, Ontario, Canada). Mitotic and apoptotic indices were obtained by counting the corresponding cells in 10 high-power fields $(400 \times)$ per given slide. This was repeated for a total of 5 slides (mean value \pm range). Necrotic index was determined by the percent of necrosis over entire area of tumor [10 highpower fields $(400 \times)$ per slide for each of 5 slides].

For immunohistochemical analysis, paraffin sections, after removal of paraffin, were permeabilized and reacted with the primary antibody (mouse anti-human-IL-2MAB202 (R\&D Systems, Minneapolis, MN) at 1:100 dilution in phosphate buffer supplemented with $5 \%$ goat serum in a moist chamber for $1 \mathrm{hr}$ at $37^{\circ} \mathrm{C}$. After washing, the slides were incubated similarly with the secondary antibody (goat anti-mouse IgG-FITC, Jackson Laboratories, Bar Harbor, ME) at a dilution of 1:1000 before washing and mounting for viewing immediately with fluorescencemicroscopy. True-positive signals were assessed qualitatively for presence or absence of sFvIL-2 by use of Image Pro 6.0 Plus software (Media Cybernetics, Silver Spring, MD).

\section{RESULTS}

\section{Development of microencapsulated cells secreting sFvIL2}

A mouse myoblast cell line, $\mathrm{C}_{2} \mathrm{C}_{12}$, was transfected via calcium phosphate precipitation with the plasmid pcDNA-
H520C9sFv-hIL-2 encoding the fusion protein sFvIL-2 (Li et al., 1999). Stable clones $(n=87)$ were screened by an ELISA directed against human IL-2, and the clone secreting the highest level of the fusion protein ( $0.41 \mathrm{ng}$ per $10^{3}$ cells per day) was chosen for encapsulation. The media from this cell line $\left(\mathrm{C}_{2} \mathrm{C}_{12} \mathrm{sFvIL-2}\right.$ ) was examined with Western blot analysis (Fig. 1) to confirm the molecular mass $(45 \mathrm{kd})$ of the fusion protein, consistent with the previously reported value (Li et al., 1999). As expected, this band was not observed in the media from the nontransfected parental cell line.

With a cell line stably expressing sFvIL-2, we further examined how effective this cell line was in expressing the transgene in the microcapsularenvironment and if the product could diffuse freely from the microcapsule membrane (Table 1). Hence, sFvIL-2 content was assayed in the media incubated with encapsulated sFvIL-2-secreting cells. The secretion of sFvIL-2 from encapsulated cells was examined weekly and compared to that of the nonencapsulated cells (Table 1, in vitro studies). Although transgene expression was transiently diminished immediately after the encapsulation process (Table 1, day 0 ), this was increased to approximately half that of the cells on a monolayer culture (Table 1, caption) within a week (Table 1, day 7). In fact, by the following week, the level of fusion protein detected in the media (Table 1, day 14) was increased to $170 \%$ compared to that of the naked cells (Table 1, caption), and maintained at least until day 21 . To test if this enhanced secretion in vitro was replicated in vivo, we implanted mice with the microencapsulated cells for varying times before retrieving them to assay for the secretion of the fusion protein

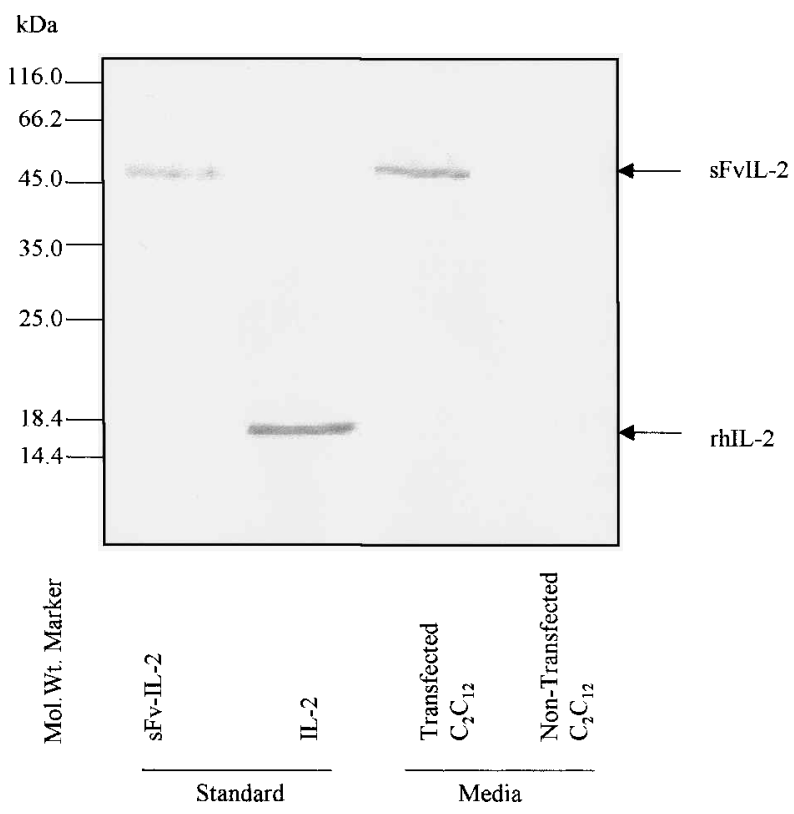

FIG. 1. Western blot to verify size of fusion protein sFvIL2. Media from microcapsules containing nontransfected $\mathrm{C}_{2} \mathrm{C}_{12}$ cells or $\mathrm{C}_{2} \mathrm{C}_{12}$ cells transfected with sFvIL-2 were concentrated and electrophoresed for Western blot using antibody directed against human interleukin-2 (hIL-2). Standards of purified hIL-2 and the fusion protein sFvIL-2 (generated by 293 sFvIL2 cells) were included as positive controls. 
Table 1. Characterization of Microencapsulated Cells for Implantation IN Vitro and IN Vivo

Days Postimplantation

$0+14$

$14 \quad 21$

sFvIL-2 secretion

(ng/1000 cells per day)

In vitro

In vivo

Viability

(cell number per capsule)

\begin{tabular}{|c|c|c|c|}
\hline In vitro & $603 \pm 66$ & $207 \pm 41$ & $678 \pm 7$ \\
\hline In vivo & $603 \pm 66$ & $550 \pm 38$ & $4261 \pm 43^{a}$ \\
\hline
\end{tabular}

Transfected $\mathrm{C}_{2} \mathrm{C}_{12}$ cells secreting $0.41 \pm 0.02 \mathrm{ng}$ sFvIL-2/1000 cells per day were encapsulated and kept either in vitro under normal tissue culture conditions or in vivo after implantation on day 0 into the mouse intraperitoneal cavities. Media were collected over a 24-hr period from either the microcapsules kept in vitro or those retrieved from the intraperitoneal implantation and returned to normal tissue culture conditions. The rates of sFvIL-2 secretion were determined by assaying for the fusion protein sFvIL-2 in the media with enzyme-linked immunosorbent assay (ELISA). The viabilities of the encapsulated cells were estimated from alamarBlue.

${ }^{a}$ Value applied to those microcapsules that were found free within the intraperitoneal cavity $(\sim 10 \%$ of the implanted capsule load).

(Table 1, in vivo studies). A similar pattern was observed: on day 0 (1 day after implantation), the retrieved microcapsules were unable to deliver any transgene product, but by day 7 postimplantation, approximately $70 \%$ more fusion protein was detected in the media from the retrieved microcapsules compared to that of the nonencapsulated cells. However, this enhanced delivery was not sustained. By day 14 postimplantation, the rate of fusion protein secretion was reduced to approximately $50 \%$ of that of the nonencapsulated cells. By day 21 postimplantation, no fusion protein was produced from the retrieved capsules.

The viability of the encapsulated cells from the retrieved microcapsules provided some insight into the reason for the diminishing level of fusion protein delivery in vivo (Table 1 , in vivo studies). Within the first week of implantation, the viability of the encapsulated cells was maintained close to the preimplantation level, thus accounting for the high level of fusion protein production on day 7 . By day 14 postimplantation, however, the number of viable cells per microcapsule increased by approximately sevenfold, this applied only to the approximately $10 \%$ of the microcapsules that remained free in the intraperitoneal cavity. The remainder of the microcapsules were found embedded in fibrotic tissue (Fig. 2A-I) and no longer contained any viable cells (data not shown). By day 21, no free microcapsule could be recovered in the intraperitoneal cavity, thus accounting for the lack of fusion protein secretion and viable cells in the in vivo samples (Table 1, day 21). This is also consistent with the decreased level of fusion protein observed in the seral compartment by day 21 (Fig. 3) as described below.

\section{Delivery of sFvIL-2-secreting microcapsules in vivo}

The efficacy of fusion protein delivery was first characterized in normal C57BL6 mice with no tumor burden (Fig. 3). The amount of IL-2 that could be measured in circulation was quantified at weekly intervals with a standard CTLL-2 assay.
In these mice, the delivery of IL-2 to the circulatory compartment was at its highest level within the first week, decreased slightly by day 14 , and dramatically to almost background level by day 21 postimplantation. The time course of delivery is correlated qualitatively with the profile of fusion protein secretion from the recovered microcapsules in vivo (Table 1). This gradual loss of circulating IL-2 was also associated with a concurrent development of antibody against the fusion protein. This was deduced from the titer of antibodies present in sera that could neutralize sFvIL-2 in an ELISA assay (Fig. 4). Such antibodies were not present at day 7, when the circulating level of sFvIL-2 was the highest in the serum. After day 14, the antibody titer continued to increase until the end of the experiment on day 28 , at which time the circulating level of sFvIL-2 was reduced to background level.

The efficacy of this system in delivering the cytokine to the various intraperitoneal organs was measured by implanting tumor-bearing mice with encapsulated sFvIL-2-secreting cells. The bioactivity associated with IL-2 was measured in various intraperitoneal organs and the tumor (Fig. 5). All the abdominal organs measured, i.e., kidney, liver, and spleen, showed elevated levels of IL-2 bioactivity while the tumor showed only approximately $20 \%$ of the organ levels. In the mock-treated controls implanted with encapsulated but nontransfected cells, the level of detectable IL-2 bioactivity was at least threefold lower in the intraperitoneal organs and twofold lower in the tumors, indicating that the enhanced IL-2 activity was associated with the implantation of encapsulated sFvIL-2-secreting cells.

\section{Efficacy in treating B16/neu tumors}

Mice injected with the experimentally determined minimal tumor dose (data not shown) of $5 \times 10^{6} \mathrm{~B} 16 /$ neu tumor cells developed palpable tumor after the first week of injection. The tumor volume increased gradually during the following week but escalated to an exponential phase of expansion from day 14 to day 18 , at which point the tumor volume reached the end 
A) I

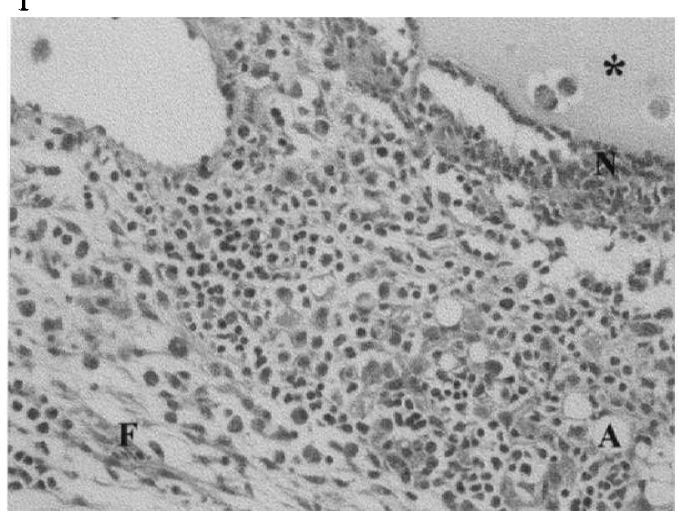

B) I

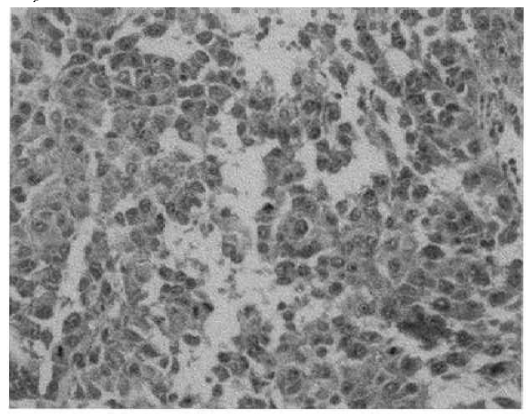

C) I

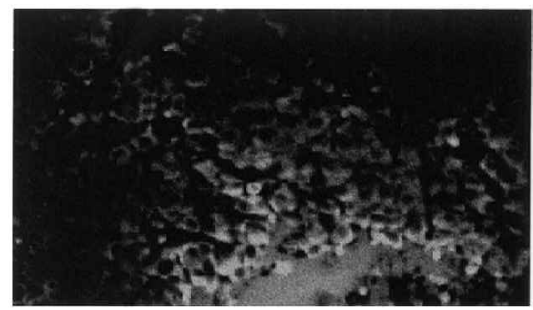

II

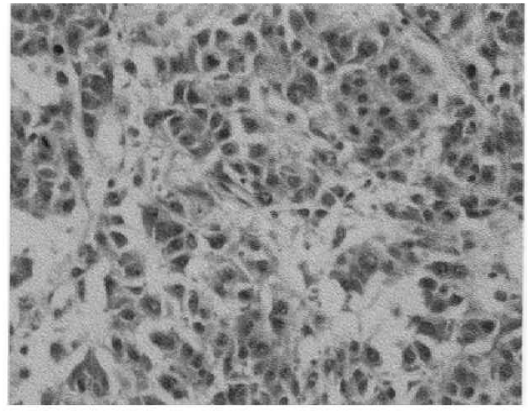

II

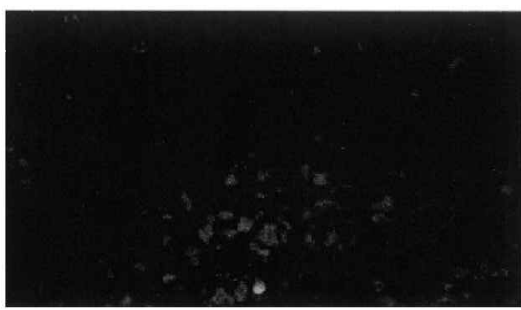

II

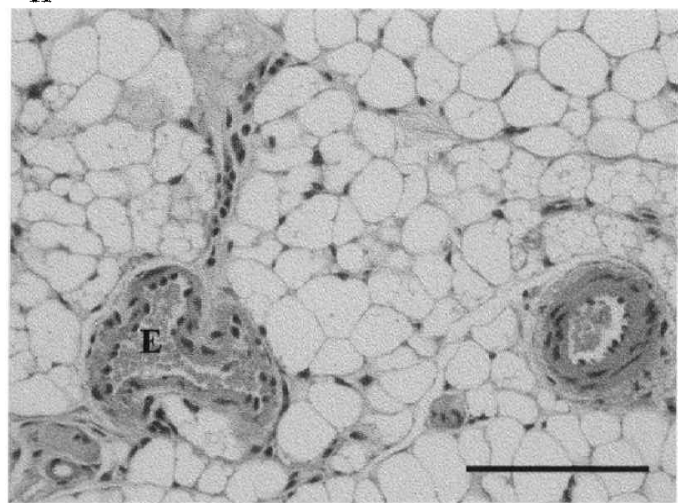

III

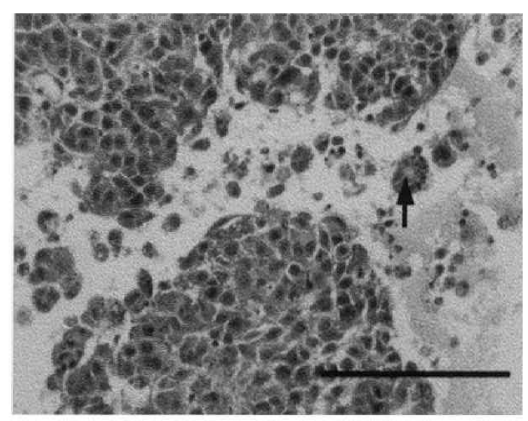

III

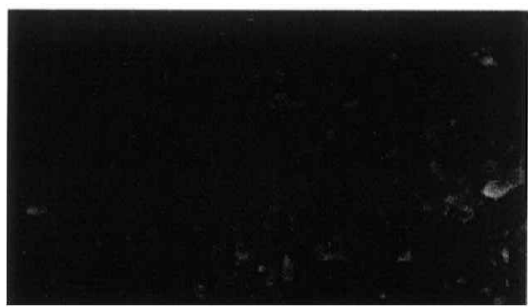

FIG. 2. Histology study of implanted microcapsules and tumors. A: The host immune response to the implanted microcapsules was observed histologically in the mesentery on day 7 postimplantation by hematoxylin and eosin (H\&E) staining (400×). A-I: Mesenteric fat with embedded capsules. Necrotic tissue was formed in the vicinity of the implanted microcapsules containing transfected $\mathrm{C}_{2} \mathrm{C}_{12}$ cells secreting sFvIL-2 but not around encapsulated nontransfected $\mathrm{C}_{2} \mathrm{C}_{12}$ cells (not shown). A microcapsule $\left(^{*}\right)$ is shown surrounded by neutrophils $(\mathrm{N})$ as well as a necrotic zone around the capsule. Fibroblastic response (F), residual small adipocytes (A) and blood vessel (b.v.) some containing erythrocytes (E) are also shown. A-II: Normal mouse mesenteric adipose tissue. Scale bar $=100 \mu \mathrm{m}$. B: H\&E staining of (B-I) untreated tumor; (B-II) mock-treated tumor; (B-III) treated tumor. No significant differences were observed between untreated and mock-treated samples, while marked changes in necrotic, apoptotic, and mitotic indices were observed in the treated tumor. Histiocytes were also observed in treated tumors (black arrow). Scale bar $=100 \mu \mathrm{m}$. C: Immunohistochemistry to detect human interleukin-2(IL-2). C-I: tumor from mouse day 7 postimplantation with encapsulated $\mathrm{C}_{2} \mathrm{C}_{12}$ cells secreting sFvIL-2; (C-II) same as (C-I) but stained without the primary antibody (negative control); (C-III) tumor from mouse day 7 postimplantation with encapsulated nontransfected $\mathrm{C}_{2} \mathrm{C}_{12}$ cells (mock-treated control). Scale bar $=100 \mu \mathrm{m}$.

point of larger than $1 \mathrm{~cm}^{3}$ so that the mice had to be killed according to institutional animal care guidelines (Fig. 6A). During this course of tumor development, the mice were implanted on day 14 with either encapsulated C2C12-sFvIL-2 cells or encapsulated nontransfected parental cells as the mock control. In the mock-control series, there was no difference in tumor progression from the untreated series and the animals also had to be killed soon after day 18 because of tumor progression. In contrast, the group treated with the encapsulated recombinant cells showed a dramatic delay in the tumor expansion. Instead of entering an exponential phase of growth after day 14, the tumors only increased in volume gradually from day 15 to day 24 (corresponding to day 7 postimplantation of microcapsules). After this point, the tumor suppression effect was no longer observed in the implanted animals, and the tumor expansion entered into the exponential phase in spite of the microcapsule treatment.

The suppression of tumor expansion by the encapsulated cells was corroborated with the improved survival of the treated animals (Fig. 6B). Hence, while only $25 \%$ of the control or 


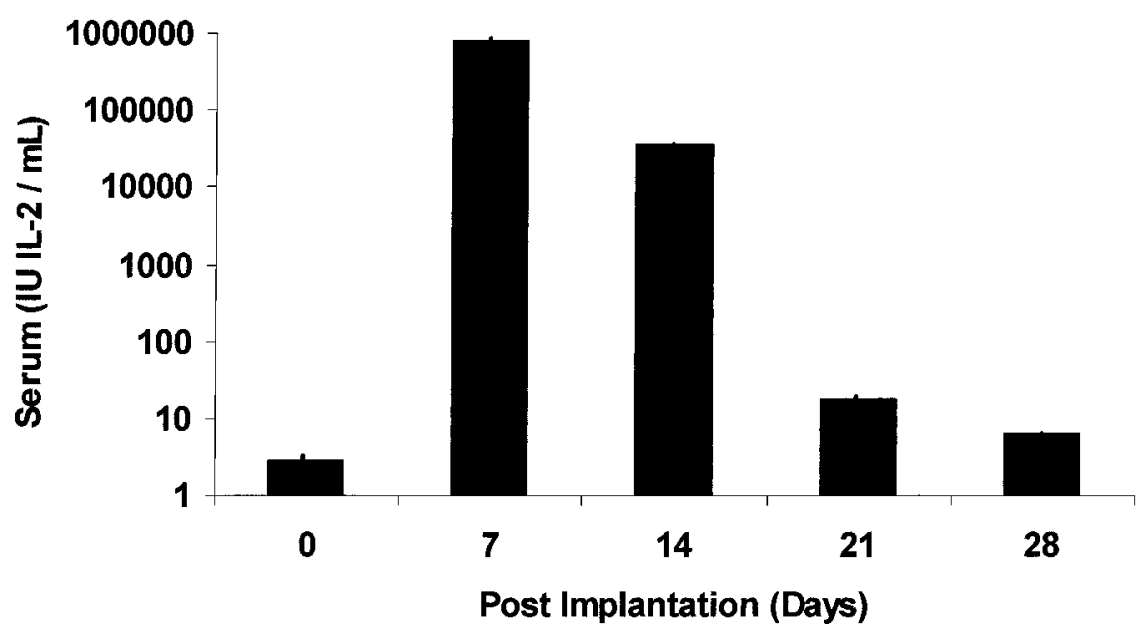

FIG. 3. Delivery of sFvIL-2 to the seral compartment. Normal mice $(n=3)$ were implanted on day 0 with encapsulated recombinant $\mathrm{C}_{2} \mathrm{C}_{12}$ cells secreting the fusion protein. At various days postimplantation, serum samples were obtained to assay for IL-2 bioactivity. Sera from mock-treated controls (mice implanted with microcapsules containing nontransfected $\mathrm{C}_{2} \mathrm{C}_{12}$ cells) or normal untreated mice showed no IL-2 bioactivity under the same conditions (data not shown).

mock-treated animals survived after day 21 of tumor cell injection, $60 \%$ of the treated animals were still alive by day 25 , and $10 \%$ survived until the end of the experiment on day 28 .

Histologic examination of liver, kidney, and spleen sections from mice treated with encapsulated $\mathrm{C}_{2} \mathrm{C}_{12}$ sFvIL-2 cells had shown some acute immune responses that were not observed in the mock-treated animals. In the liver, hepatocytes showed signs of vacuolation and ballooning consistent with an acute inflammatory response. Similar staining of spleen sections from these mice had shown a marked increase in the volume of the lymphocyte-containing white pulp, which showed activation by follicle formation. Gross anatomic examination of euthanized mice 7-10 days postimplantation of encapsulated $\mathrm{C}_{2} \mathrm{C}_{12}$ sFvIL2 cells showed some fibrous tissue development around the microcapsules that were not seen with encapsulated parental $\mathrm{C}_{2} \mathrm{C}_{12}$ cells. This tissue and the mesenteric embedded capsules were processed for H\&E staining to show the surrounding inflammatory exudate including fibrin, neutrophils, histocytes, and a zone of necrotic cellular debris around the microcapsules. This caused some local destruction of the mesenteric adipose tissue (Fig. 2A-I), in contrast to untreated, healthy mouse mesentery (Fig. 2A-II).

The tumor deposits were examined histologically 7 days after microcapsule implantation (Fig. 2B, 2C). Untreated (Fig. 2B-I) and mock-treated (Fig. 2B-II) tumors examined with $\mathrm{H} \& \mathrm{E}$ staining showed no obvious histologic differences in terms of size, mitotic activities, or areas of necrosis. However, tumors from mice that were treated with the encapsulated $\mathrm{C}_{2} \mathrm{C}_{12}$ sFvIL-2 cells (Fig. 2B-III) showed a dramatic inflammatory response. Apoptotic cells as well as necrotic debris were significantly increased $(p<0.001)$ in addition to a decrease in mitotic index $(p<0.01)$. Comparing the untreated and mock-

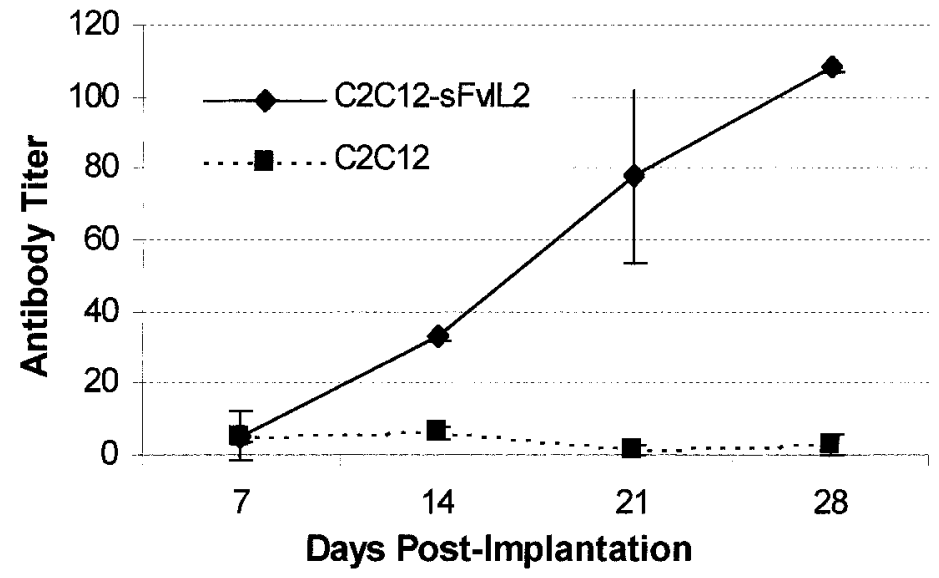

FIG. 4. Host Immune reaction against secreted sFvIL-2 and implanted microcapsules. Mice were implanted intraperitoneally on day 0 with microcapsules containing either transfected $\mathrm{C}_{2} \mathrm{C}_{12}$ cells secreting sFvIL-2 or nontransfected $\mathrm{C}_{2} \mathrm{C}_{12}$ cells $(n \geq 3$ in each group). Development of antibody in the sera against the fusion protein sFvIL-2 was followed from day 0 to day 28 . The antibody titer is expressed as micrograms $(\mu \mathrm{g})$ of sFvIL-2 neutralized per microliter $(\mu \mathrm{l})$ of serum. 


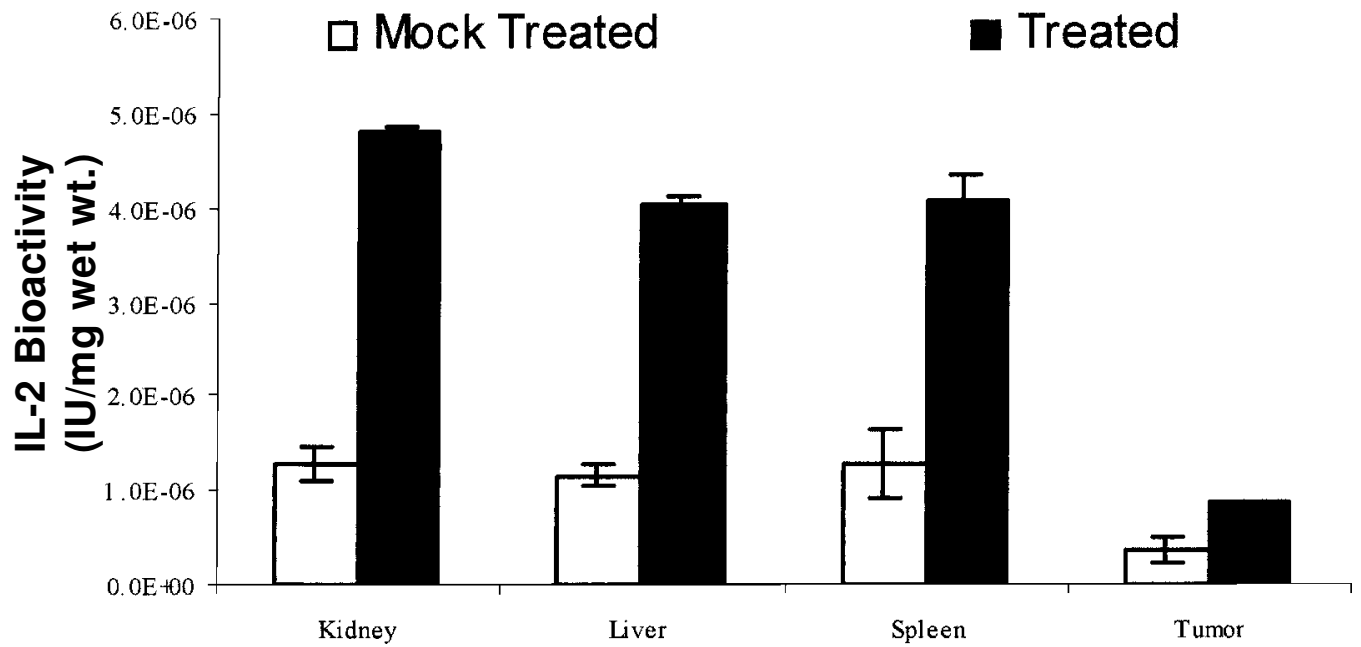

FIG. 5. Interleukin-2 (IL-2) levels in various tissues. Tumor-bearing mice were implanted with microcapsules containing either nontransfected $\mathrm{C} 2 \mathrm{C} 12$ cells (mock-treated) or fusion-protein-secreting C2C12-sFvIL-2 cells (treated) on day 0 ( $n=3$ in each group). On day 7 postimplantation, the mice were killed and various organs and the tumors were removed to assay for IL-2 biologic activity. The units are expressed as average international unit (IU) per milligram (mg) of protein \pm standard deviation (SD).
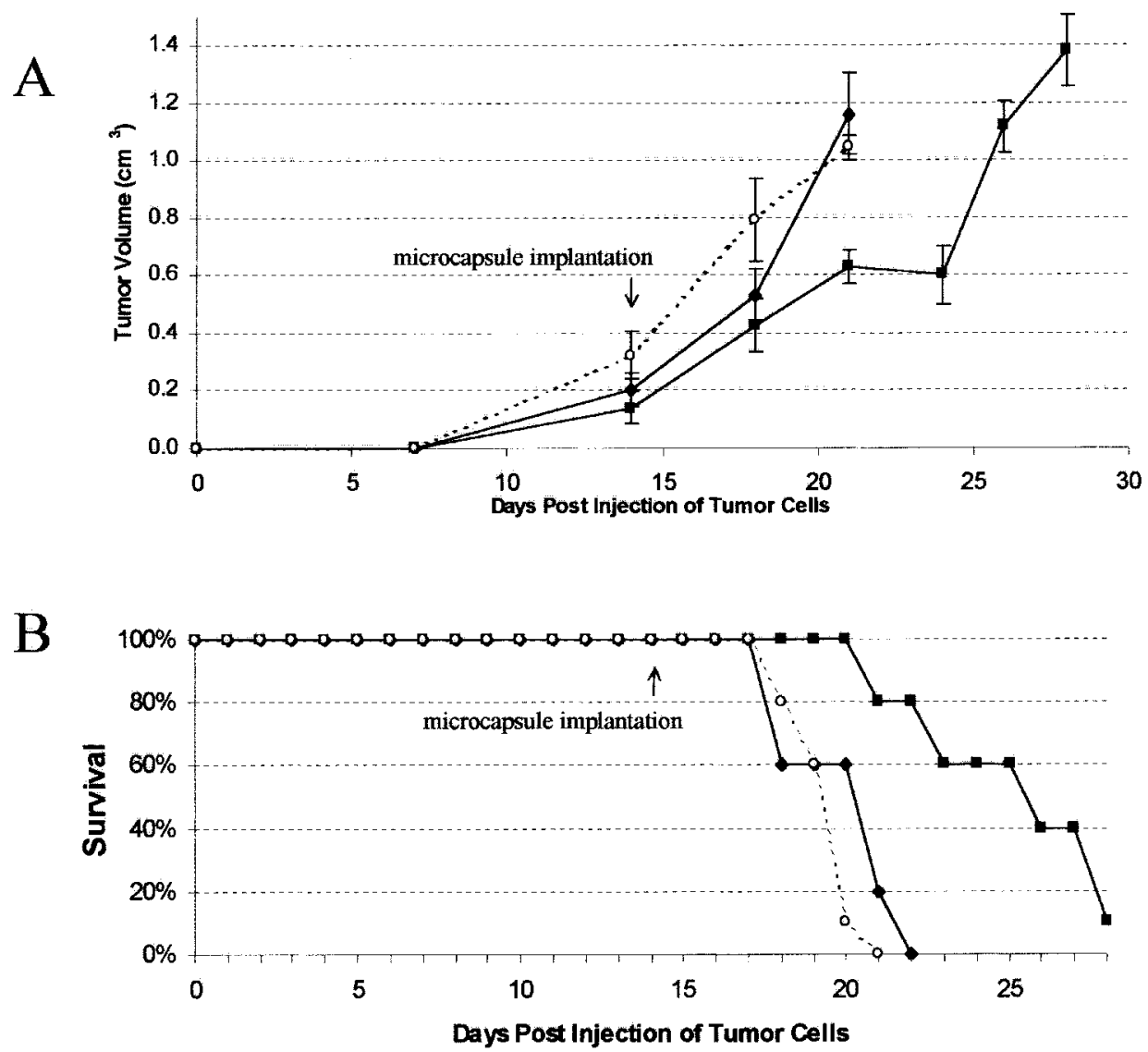

FIG. 6. Tumor suppression and life-span extension with immunoisolation. A: Time course of tumor progression. Mice were injected with tumor cells on day 0 and were either left untreated $(\bigcirc, n=10)$, mock-treated with encapsulated parental $\mathrm{C}_{2} \mathrm{C}_{12}$ cells $(\diamond, n=10)$ or treated with encapsulated $\mathrm{C}_{2} \mathrm{C}_{12}$ sFvIL-2 cells secreting sFvIL-2 $(\boldsymbol{\square}, n=10)$. The size of the palpable tumors was measured at various days postinjection. Error bars represent standard errors of the mean for each value plotted. B: Time course of mice survival. Survival plot of the mice depicted in (A) when they were considered to have reached their end point on their tumors arriving at a volume of $1 \mathrm{~cm}^{3}$. 
treated tumors, the treatment with encapsulated $\mathrm{C}_{2} \mathrm{C}_{12} \mathrm{sFvIL-2}$ cells led to an increase of twofold to threefold increase in apoptotic (Fig. 7-I) and necrotic (Fig. 7-II) indices in the tumor tissue. In addition, immunohistochemical analysis for the humanized sFvIL-2 at the tumor confirmed the presence of the immunoconjugate at the B16/neu cells, which were not present in either the untreated or the mock-treated controls (Fig. 2C). The presence of the positive signal in the cytoplasmic compartment of the tumor cells indicated the internalization of the transgene product delivered (Fig. 2C-I).

\section{DISCUSSION}

The feasibility of delivering a fusion protein sFvIL-2 of the correct molecular weight (Fig. 1) with IL-2 bioactivity has now been shown both in vitro and in vivo from encapsulated cells (Table 1, Fig. 3). Media from the microcapsules kept under normal tissue culture condition or retrieved from the mouse intraperitoneal cavity after implantation showed continued fusion protein secretion (Table 1). However, after 21 days of implantation in mice, the microcapsules were no longer capable of delivering the fusion protein. The reason for this is likely the inflammatory and antigenic responses in the host to be discussed later. That this fusion protein was delivered to the recipient was shown by the significant levels of IL-2 delivered to the serum (Fig. 3) and the intraperitoneal organs such as kidney, spleen, and liver (Fig. 5). Most important, the targeting of the fusion protein to the tumor was achieved as shown with immunohistochemical analysis (Fig. 2C).

Once the fusion protein binds to tumor cells through the antibody portion, the local concentration of IL-2 is increased, which in turn should attract and bind to host $\mathrm{T}$ cells in the vicinity through the IL-2 receptor. This local activation of $\mathrm{T}$ cells presented within the proper major histocompatibility complex (MHC) I context, should activate the downstream signals required in T-cell activation for cell-mediated killing. IL-2 occupies a central role in the augmentation of cell-mediated immune responses by stimulating and supporting a broad range of immune cells in vitro and in vivo, including $\mathrm{T}$ and $\mathrm{B}$ cells, macrophages, and natural killer cells (NK), as well as stimulating the production of lymphokine-activated killer (LAK) cells derived from NK cells that can effectively mediate antibody-dependent cellular toxicity. These multiple immune responses caused by the delivery of IL-2 should account for the significantly increased levels of tumor cell apoptosis (Fig.7-I) as well as necrosis (Fig. 7-II). The twofold increase in apoptotic and necrotic indices in the tumors from mice receiving encapsulated sFvIL-2 cells is consistent with localized IL-2 mediated therapy (Gillies et al., 1992). Other cytokines such as IL-4 or IL-13 have been delivered via xenogeneic encapsulated cells for the treatment of collagen-inducedarthritis, and efficacy was also demonstrated by a significant reduction in the severity of the articular disease (Bessis et al., 1999). Hence, the delivery of a bioactive cytokine to a localized site is an achievable goal.

The end-point analysis of tumor development is perhaps of greater clinical importance. It is now shown that the delivery of the fusion protein via microencapsulated cells can lead to a significant retardation of tumor progression, concomitant with an improved life span in the treated animals (Fig. 6). However, the improvements in clinical outcomes are short-lived, lasting for the first 7-10 days after implantation before tumor progression resumed at the untreated rate. This coincided with a dramatic decrease in circulating level of IL-2 (Fig. 3, day 21), as well as an emerging high level of antibodies against the fusion protein (Fig. 4). Furthermore, the encapsulated cells retrieved from the implanted animals at this later time point (day 21) were no longer secreting the fusion protein (Table 1, in vivo studies).

The loss of long-term efficacy observed above may be attributed in part to the xenogeneic human origin of the fusion protein. When a xenogeneic (human factor IX into mice) or a novel therapeutic gene product (mouse $\beta$-glucuronidase to a null-mutant mouse) was delivered, an antigenic response is triggered, associated with rapid clearance of the delivered transgene product (Hortelano et al., 1996), and loss of long-term efficacy (Ross et al., 2000a). However, such antigenic response can be suppressed (Potter et al., 1998), leading to restoration of effective delivery of the trangene product (Ross et al., 2000a). Because no host immune responses were triggered by alginate encapsulated monkey CV1 cells secreting murine IL-4, IL-5 or interferon- $\gamma$ (IFN- $\gamma$ ) (all type II cytokines) in
I)

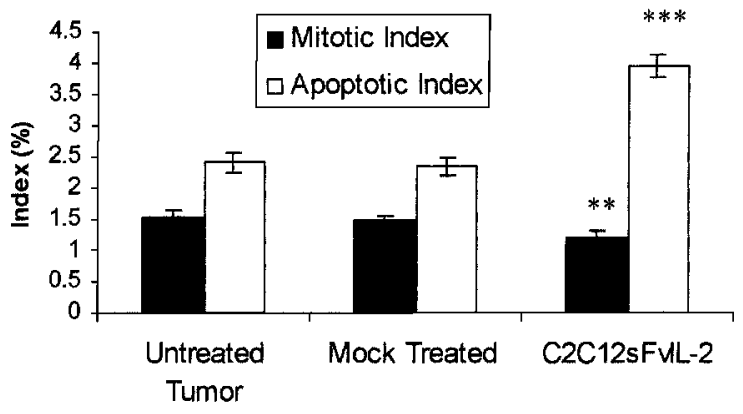

II)

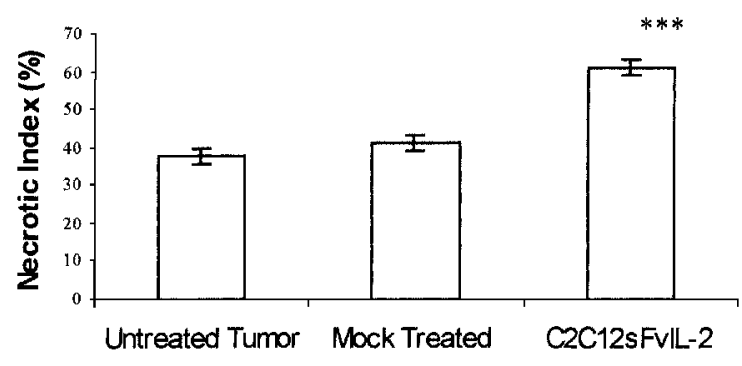

FIG. 7. Pathologic indices of the tumor. From the hematoxylin and eosin (H\&E)-stained slides, mitotic, apoptotic, and necrotic indices were compared among the tumors from three groups of mice: untreated controls, mock-treated controls implanted with encapsulated parental cells, and treated mice implanted with encapsulated cells secreting the fusion protein ( $n=3$ per group). Significant difference from untreated and sham controls $(* * p<0.01, * * * p<0.001)$. 
mice, or encapsulated Chinese hamster ovary (CHO) cells secreting the murine IFN- $\alpha$ (a type-1 cytokine) (Savelkoul et al., 1994), it is likely that the lack of long-term IL-2 delivery observed (Table 1, Fig. 6) is a problem that may be resolved by using a murine-derived fusion protein instead. This is supported when syngeneic proteins were delivered in other studies using this technology. These studies confirmed the delivery of transgene products for up to 178 days in mice receiving mouse growth hormone (Al-Hendy et al., 1995).

However, concurrent with the observed decrease in the delivery of IL-2 into serum (Fig. 3) and increase in neutralizing antibodies against the fusion protein (Fig. 4), we also observed fibroblastic tissue reaction surrounding the microcapsules containing $\mathrm{C}_{2} \mathrm{C}_{12}$ sFvIL-2 cells (Fig. 2A-I). Such inflammatory response was not observed in mice implanted with encapsulated parental $\mathrm{C}_{2} \mathrm{C}_{12}$ cells (data not shown). The microcapsules were encapsulated by an acute and chronic inflammatory response with neutrophils and fibrous tissue. The surrounding native tissue did show some local necrosis, with only a few viable cells remaining within the capsules. This inflammatory response may have caused the loss of continued fusion protein production from the microcapsules after 21 days of implantation (Table 1, in vivo studies). However, no indicators of chronic inflammation were observed. Although the antibody response (Fig. 4) is likely because a humanized protein was being delivered, the tissue responses, including the acute inflammation and the high local necrosis are consistent with high levels of IL-2 bioactivity in the peritoneal cavity, a reaction also observed in rats (Siegel and Puri, 1991). Hence, although the delivery of cytokines via this approach has been shown to be feasible, such immune responses to the delivered cytokines should certainly be assessed and anti-inflammatory medication may be indicated. As of yet, no general rule can be applied toward the effects of delivering potent immune-stimulating compounds from such implantable device, since no host immune responses were triggered by alginate-encapsulated monkey CV1 cells secreting murine IL-4 or IL-5 in mice, or encapsulated CHO cells secreting the murine IFN- $\alpha$ (a type-1 cytokine) (Savelkoul et al., 1994).

In theory, recombinant molecules with ability to disrupt cancer progression via a variety of metabolic pathways may be considered for this delivery platform (Cirone et al., 2001). Efficacy in using encapsulation for the treatment of pancreatic cancer by enhanced prodrug metabolism (Kröger et al., 1999), and treatment of glioma through endostatin delivery (Joki et al., 2001; Read et al., 2001) has already been demonstrated. The advantages of this approach are efficiency, safety, and potential cost effectiveness. Once a recombinant cell line has been created, it can be used for all recipients requiring the same recombinant product replacement. It can be stored indefinitely until needed, thoroughly characterized for quality-control purposes before implantation, and requires no patient-specific genetic manipulation. The approach is surgically benign via injection with syringe or catheter. Standard cell lines for implantation are genetically modified by chemical transfection without recourse to viral vectors, thus removing concerns about viral recombinantion, uncontrolled dissemination, insertional mutagenesis or host-cell damage from irreversible genetic alteration of the recipient's own cells. Furthermore, the microcapsules are potentially retrievable. In principle, the "treatment" can be terminated when desired by removing the microcapsules in case of unanticipated adverse reaction, thus offering additional control and safety. In addition, the recombinant product is delivered in situ continuously and in low doses, thus obviating the need for product purification and repeated bolus injection. The costs of product purification and repeat administrations, and the toxicity of high-dose delivery by bolus injection are considerably reduced.

In conclusion, an alternative approach to treating cancer through systemic delivery of a tumor-targeted cytokine with microencapsulation of recombinant cells is a feasible goal. The many advantages of this delivery system are further enhanced by the platform nature of this technology, amenable to the delivery of molecules important in a variety of pathways that can intervene cancer progression (Cirone et al., 2001). For these reasons, delivery of recombinant gene products for cancer therapy via microencapsulation is a scientifically and clinically viable concept (Chang et al., 1999).

\section{ACKNOWLEDGMENTS}

We would like to thank the Canadian Breast Cancer Research Initiative and the Medical Research Council of Canada for support of this work. P. Cirone is the recipient of the McMaster University Graduate Scholarship, and R.C. Austin is the recipient of a career investigator award from the Heart and Stroke Foundation of Ontario. We would also like to thank Drs. Yonghong Wan, and Jonathan Bramson for helpful suggestions in the development of this cancer model, and Drs. Bradley White and Carl Richards for their advice throughout the development of this work in partial fulfillment of P. Cirone's doctoral degree requirements.

\section{REFERENCES}

ADDISON, C.L., BRACIAK, T., RALSTON, R., MULLER, W.J., GAULDIE, J., and GRAHAM, F.L. (1995). Intratumoral injection of an andenovirus expressing interleukin-2 induces regression and immunity in a murine breast cancer model. Proc. Natl. Acad. Sci. U.S.A. 92, 8522-8526.

AL-HENDY, A., HORTELANO, G., TANNENBAUM, G.S., and CHANG, P.L. (1995). Correction of the growth defect in dwarf mice with nonautologous microencapsulated myoblasts: An alternate approach to somatic gene therapy. Hum. Gene Ther. 6, 165-175.

AL-HENDY, A., HORTELANO, G., TANNENBAUM, G.S., and CHANG, P.L. (1996). Growth retardation: An unexpected outcome from growth hormone gene therapy in normal mice with microencapsulated myoblasts. Hum. Gene Ther. 7, 61-70.

BASELGA, J., TRIPATHY, D., MENDELSOHN, J., BAUGHMAN, S., BENZ, C.C., DANTIS, L., SKLARIN, N.T., SEIDMAN, A.D., HUDIS, C.A., MOORE, J., ROSEN, P.P., TWADDELL, T., HENDERSON, I.C., and NORTON, L. (1996). Phase II study of weekly intravenous recombinant humanized anti-p $185^{\mathrm{HER} 2}$ monoclonal antibody in patients with HER2/neu-overexpressing metastatic breast cancer. J. Clin. Oncol. 14, 737-744.

BASElGA, J., SEIDMAN, A.D., ROSEN, P. P., and NORTON, L., (1997). HER2 overexpression and paclitaxel sensitivity in breast cancer: Therapeutic implications. Oncology 11(3 Suppl 2), 43-48.

BECKER, J. C., VARKI, N., GILLIES, S.D., FURUKAWA, K., and REISFELD, R.A. (1996). An antibody-interleukin 2 fusion protein 
overcomes tumor heterogeneity by induction of a cellular immune response. Proc. Natl. Acad. Sci. U.S.A. 93, 7826-7831.

BESSIS, N., HONIGER, J., DAMOTTE, D., MINTY, A., FOURNIER, C., FRADELIZI, D., and BOISSIER, M. (1999). Encapsulation in hollow fibres of xenogeneic cells engineered to secrete IL-4 or IL13 ameliorates murine collagen-induced arthritis (CIA). Clin. Exp. Immunol. 117, 376-382.

CHANG, P.L. (1994). Calcium phosphate-mediated DNA transfection. In Gene Therapeutics. J.A. Wolff, ed. (Dirkhauser Boston, Boston, MA) pp. 157-179.

CHANG, P.L. (1995). Nonautologous somatic gene Therapy. In Somatic Gene Therapy. P.L. Chang, ed. (CRC Press, Ann Arbor, MI) pp. 203-224.

CHANG, P.L., VAN RAAMSDONK, J.M., HORTELANO, G., BARSOUM, S.C., MACDONALD, N.C., and STOCKLEY, T.L. (1999). The in vivo delivery of heterologous proteins by microencapsulated recombinant cells. Trends Biotechnol. 17, 78-83.

CIRISANO, F.D., and KARLAN, B.Y. (1996). The role of HER-2/neu oncogene in gynecologic cancers. J. Soc. Gynecol. Invest. 3, 99-105.

CIRONE, P., SALLER, R.M., and CHANG, P.L. (2001). Immuno-isolation in oncology: A mini-review. Curr. Pharm. Biotechnol. 2, 269-277.

GILLIS, S., FERM, M.M., OU, W., and SMITH, K. (1978). T cell growth factor: Parameters of production and a quantitative microassay for activity. J. Immunol. 120, 2027-2032.

GILLIES, S.D., REILLY, E. B., LO, K-M., and REISFELD, R.A. (1992). Antibody-targeted interleukin 2 stimulates T-cell killing of autologous tumor cells. Proc. Natl. Acad. Sci. U.S.A. 89, 1428-1432.

HEIKE, Y., TAKAHASHI, M., OHIRA, T., NARUSE, I., HAMA, S., OHE, Y., KASAI, T., FUKUMOTO, H., OLSEN, K.J., PODACK, E.E., and SAIJO, N. (1997). Genetic immunotherapy by intrapleural, intraperitoneal and subcutaneous injection of IL-2 gene-modified Lewis lung carcinoma cells. Int. J. Cancer. 73, 884-849.

HOFFMAN, D.M., and FIGLIN, R.A. (2000). Intratumoral interleukin 2 for renal-cell carcinoma by direct gene transfer of a plasmid DNA/DMRIE/DOPE lipid complex. World J. Urol. 18, 152-156.

HORTELANO, G., AL-HENDY, A., OFOSU, F.A., and CHANG, P.L. (1996). Delivery of human factor IX in mice by encapsulated recombinant myoblasts: A novel approach towards allogeneic gene therapy of hemophilia B. Blood 87, 5095-5103.

HYNES, N.E., and STERN, D.F. (1994). The biology of erB-2/neu/HER2 and its role in cancer. Biochim. Biophys. Acta 1198, 165-184.

JOKI, T., MACHLUF, M., ATALA, A., ZHU, J., SEYFRIED, N.T., DUNN, I.F., ABE, T., CARROLL, R.S., and BLACK, P.M. (2001). Continuous release of endostatin from microencapsulated engineered cells for tumor therapy. Nat. Biotechnol. 19, 35-39.

KRÖGER, J.C., BERGMEISTER, H., HOFFMEYER, A., CEIJNA, M., KARLE, P., SALLER, R., SCHWENDENWEIN, I., VONROMBS, K., LIEBE, S., GUNZBERG, W.H., SALMONS, B., HAUENSTEIN, K., LOSERT, U., and LÖHR, M. (1999). Intraarterial instillation of microencapsulated cells in the pancreatic arteries in pig. Ann. N.Y. Acad. Sci. 880, 374-378.

LI, J., GYORFFY, S.F., RING, D.B., KWOK, C.S., and AUSTIN, R.C. (1999). Preparation and characterization of a recombinant humanized single-chain Fv antibody/human interleukin-2 fusion protein directed against the HER-2/neu (c-erbB2) proto-oncogene product, p185. Tumor Targeting 4, 105-114.

MEDEN, H., and KUHN, W. (1997). Overexpression of the oncogene c-erbB-2 (HER2/neu) in ovarian cancer: A new prognostic factor. Eur. J. Obstet. Gynecol. Reprod. Biol. 71, 173-179.

PEIRONE, M., ROSS, C.J.D., HORTELANO, G., BRASH, J.L., and CHANG, P.L. (1998). Encapsulation of various recombinant mammalian cell types in different alginate microcapsules. Biomaterials 42, 587-596.

PEGRAM, M.D., LIPTON, A., HAYES, D.F., WEBER, B.L., BASELGA, J.M., TRIPATHY, D., BALY, D., BAUGHMAN, S.A., TWADDELL, T., GLASPY, J.A., and SLAMON, D.J. (1998) Phase II study of receptor-enhanced cheomsensistivity using recombinant humanized anti-p $185^{\mathrm{HER} 2 / \text { neu }}$ monoclonal antibody plus cisplatin in patients with HER2/neu-overexpressing metastatic breast cancer refractory to chemotherapy treatment. J. Clin. Oncol. 16, 2659-2671. POTTER, M.A., HYMUS, S., STOCKLEY, T., and CHANG P.L. (1998) Suppression of immunological response against a transgene product delivered from microencapsulated cells. Hum. Gene Ther. 9, 1275-1282. READ, T.A., SORENSEN, D.R., MAHESPARAN, R., ENGER, P.O., TIMPL, R., OLSEN, B.R., HJELSTUEN, M.H., HARALDSETH, O., and BJERKVIG, R. (2001). Local endostatin treatment of gliomas by microencapsulated producer cells. Nat. Biotechnol. 19, 29-34.

ROSENBERG, S.A., LOTZE M.T., YANG, J.C., AEBERSOLD P.M., LINEHAN, W.M., SEIPP, C.A., and WHITE, D.E. (1989). Experience with the use of high-dose interleukin-2 in the treatment of 652 cancer patients. Ann Surg. 210, 474-485.

ROSENBERG, S.A. (1997). Keynote address: Perspectives on the use of interleukin-2 in cancer treatment. Cancer J. Sci. Am. 3(Suppl 1), S2-6.

ROSENSTEIN, M., ETTINGHAUSEN, S.E., and ROSENBURG, S.A. (1986). Extravasation of intravascular fluid mediated by the systemic administration of recombinant interleukin-2. J. Immunol. 137, 1735-1742.

ROSS, C.J.D., BASTEDO, L., MAIER, S.A., SANDS, M.S, and CHANG, P.L. (2000a). Somatic gene therapy of a lysosomal storage disease, mucopolysaccharidosis VII, with microencapsulated recombinant cells. Hum. Gene Ther. 11, 2117-2127.

ROSS, C.J.D., RALPH, M., and CHANG, P.L. (2000b). Somatic gene therapy of a neurodegenerative lysosomal storage disease using microencapsulated recombinant cells. Exp. Neurol. 166, 276-286.

SAMBROOK, J., FRITSCH, E.F., and MANIATIS, T. (1989) Molecular Cloning: A Laboratory Manual, 2nd ed. (Cold Spring Harbor Laboratory Press, Plainview, NY).

SAVELKOUL, H.F., VAN OMMEN, R., VOSSEN, A.C., BREEDLAND, E.G., COFFMAN, R.L., and VAN OUDENAREN, A. (1994). Modulation of systemic cytokine levels by implantation of alginate encapsulated cells. J. Immunol. Methods 170, 185-196.

SIEGEL, J.P., and PURI, R.K. (1991). Interleukin-2 toxicity. J. Clin. Oncol. 9, 694-704.

VAN RAAMSDONK, J.M., and CHANG, P.L. (2001). The osmotic pressure test: A simple, quantitative method to assess the mechanical stability of alginate microcapsules. J. Biomed. Mater. Res. 54, 264-271

VAN RAAMSDONK, J.M., ROSS, C.J.D., POTTER, M.A, KURACHI, S., KURACHI, K., STAFFORD, D.W., and CHANG, P.L. (2002). (2001) Treatment of hemophilia B in mice with non-autologous somatic gene therapeutics. J. Lab. Clin. Med. 139, 35-42.

XIANG, J., LIU, E., MOYANA, T., and QI, Y. (1994). Single-chain antibody variable region-targeted interleukin-2 stimulates T cell killing of human colorectal carcinoma cells. Immunol. Cell Biol. 72, 275-285.

Address reprint requests to: Patricia L. Chang, M.D. Department of Pediatrics Health Sciences Centre Room $3 N 18$ McMaster University 1200 Main Street West Hamilton, Ontario L8N $3 Z 5$ Canada

E-mail: changp@mcmaster.CA

Received for publication December 10, 2001; accepted after revision May 23, 2002.

Published online: June 12, 2002. 